\title{
The Use of a Personal Computer as Analyzer of Power Quality
}

\author{
Andrei S. Meshcheryakov and Vasily I. Panteleev* \\ Siberian Federal University \\ 79 Svobodny, Krasnoyarsk, 660041, Russia
}

Received 13.01.2016, received in revised form 29.04.2016, accepted 18.07.2016

The possibility of using a personal computer as an analyzer of power quality and the results of tests of the laboratory sample instrument.

Keywords: the quality of electric power, personal computer, sound card, multiplexer, voltage, current, frequency, power, harmonic, power factor.

Citation: Meshcheryakov A.S., V.I. Panteleev. The use of a personal computer as analyzer of power quality, J. Sib. Fed. Univ. Eng. technol., 2016, 9(6), 928-932. DOI: 10.17516/1999-494X-2016-9-6-928-932.

\section{Применение персонального компьютера \\ как анализатора качества электрической энергии}

\author{
А.С. Мещеряков, В.И. Пантелеев \\ Сибирский федеральный университет \\ Россия, 660041, Красноярск, Свободньй, 79
}

Обоснована возможность применения персонального компьютера как анализатора качества электрической энергии и представлены результаты испытаний лабораторного образца прибора.

Ключевые слова: качество электрической энергии, персональный компьютер, звуковая карта, мультиплексор, напряжение, ток, частота, мощңность, гармонические составляющие, коэффициент мощности.

В условиях функционирования рынка электрической энергии и мощности усиливаются требования к качеству электроэнергии. Более того, анализ мировых тенденций показывает, что такие требования в дальнейшем будут только ужесточаться. Качество электрической энергии (КЭ) определяется совокупностью ее характеристик, при которых электроприёмники могут нормально работать и выполнять заложенные в них функции.

(C) Siberian Federal University. All rights reserved

* Corresponding author E-mail address: pvi0808@rambler.ru 
В настоящее время для контроля КЭ на рынке представлено большое количество специальных приборов российских и зарубежных производителей, однако при всех положительных свойствах они имеют, по крайней мере, один недостаток- высокую цену. В статье предпринята попытка создания простого и доступного для персонала предприятий анализатора КЭ.

Проведенные эксперименты показали, что современный персональный компьютер (ноутбук, нетбук, сенсорная панель), включающий в себя стандартные устройства и порты вводавывода, может быть использован для создания трехфазного анализатора качества электрической энергии. Разработанный авторами статьи анализатор качества электрической энергии на данный момент способен анализировать шесть основных показателей качества согласно ГОСТ Р 54149 - 2010 «Нормы качества электрической энергии в системах электроснабжения общего назначения»:

- установившееся отклонение напряжения $\delta U_{\mathrm{y}}$;

- размах изменения напряжения $\delta U_{t}$;

- коэффициент $n$-й гармонической составляющей напряжения $\mathrm{k} U(n)$;

- отклонение частоты $\Delta f$;

- длительность провала напряжения $t_{\text {п; }}$;

- импульсное напряжение $U_{\text {имп }}$.

Прибор измеряет также ток, частоту, коэффициент мощности, мощность (активную, реактивную, полную), осциллографирует с высокой точностью напряжение и ток (длительность зависит от емкости накопителей информации персонального компьютера и может составлять теоретически до нескольких месяцев).

Определение показателей качества электрической энергии - довольно сложная задача. Большинство процессов, протекающих в электрических сетях, быстротекущие, все нормируемые показатели качества электрической энергии не могут быть измерены напрямую: их необходимо рассчитывать, а окончательное заключение о КЭ можно дать только по статистически обработанным результатам. Для определения показателей качества электрической энергии необходимо выполнить большой объём измерений с высокой скоростью и одновременной математической и статистической обработкой измеренных значений, что предполагает применение компьютера с вычислительной архитектурой не ранее Pentium IV.

Для построения анализатора качества необходимо с высокой точностью зафиксировать изменения токов и напряжений на большом временном интервале. Для этих целей подходит современная звуковая карта, встроенная в большинство материнских плат персональных компьютеров.

В рамках статьи рассмотрено только определение высших гармонических в структуре силового сигнала. Данная задача приоритетна при анализе КЭ и сравнительно сложно реализуется алгоритмически.

Трехфазный анализатор качества электроэнергии на базе персонального компьютера возможен только при наличии у звуковой карты шести записывающих каналов или внешнего мультиплексора, выполняющего попарно переключение выходных каналов силовой сети к входным каналам звуковой карты (рис. 1). Управление мультиплексором тоже может быть организовано с помощью звуковой карты. Лабораторная модель разработанного анализатора КЭ

$$
\text { - } 929 \text { - }
$$




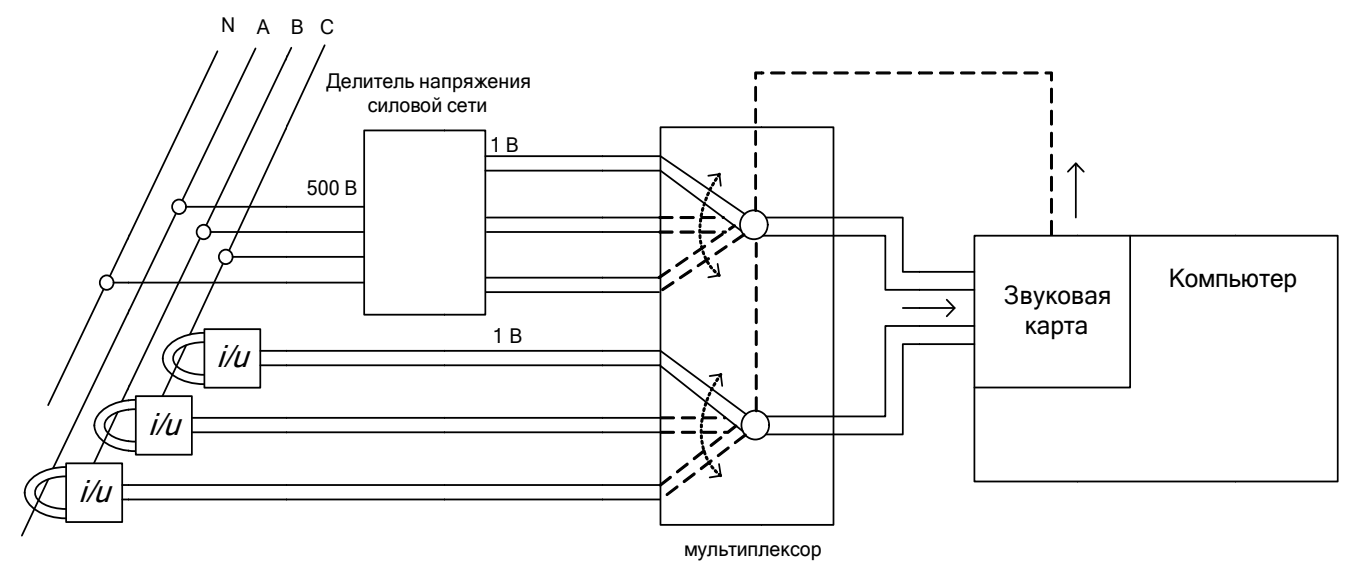

Рис. 1. Структурная схема трехфазного анализатора КЭ

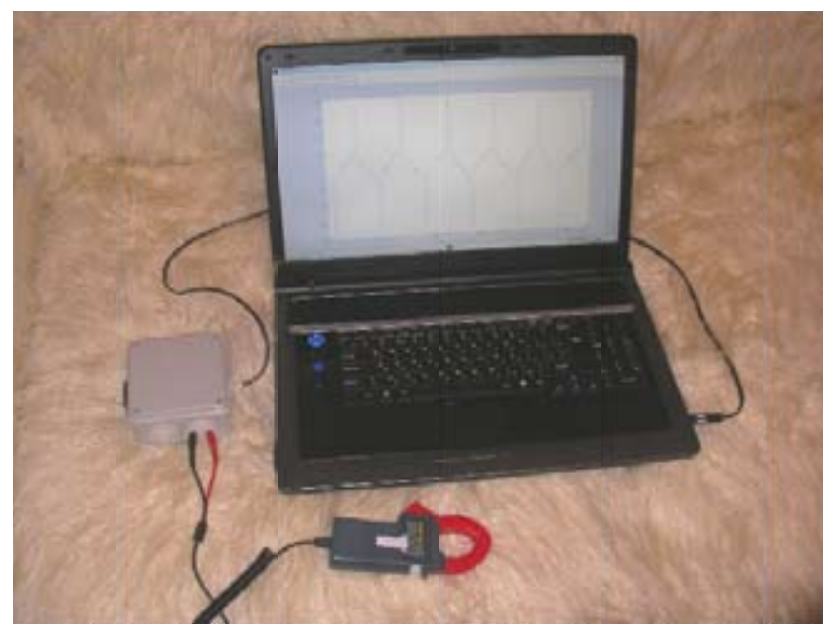

Рис. 1. Структурная схема трехфазного анализатора КЭ

в однофазном варианте представлена на рис. 2. Следует отметить, что силовой сигнал должен быть нормирован к допустимому входному напряжению звуковой карты.

Современные встроенная или внешняя звуковые карты имеют частоту дискретизации до 192 кГц и число уровней квантования $-2^{16}$, число фиксирующих каналов от 2 до 8 . Действующее значение амплитуды входного сигнала не должно превышать 1 В. С учетом динамического диапазона звуковой карты точность оцифровки силового напряжения 500 В составит 500/65535=0,00763 В (для 24-битной звуковой карты точность составляет около 0,0000298 В).

Уровень собственных шумов звуковой карты уменьшает точность оцифровки на порядок, но, тем не менее, она значительно выше, чем у самых дорогих промышленных анализаторов КЭ. Учитывая частоту дискретизации современной звуковой карты в 192 кГц, возможно получение 3840 мгновенных временных значений силового сигнала за один период частотой 50 Гц. Такого числа независимых измерений силового сигнала достаточно для разложения последнего до 1920 гармоник. 
Стабильность и точность современных аналого-цифровых преобразователей звуковых карт гарантируется миллиардными серийными образцами, а стоимость при этом на несколько порядков ниже, чем у АЦП промышленных анализаторов КЭ.

С помощью разработанного анализатора КЭ для определения высших гармонических в структуре силового сигнала была проанализирована осциллограмма напряжения (рис. 3), зафиксированная для реальной силовой сети в административном здании (величина напряжения в относительных единицах).

Для определения высших гармонических в структуре силового сигнала выполним линейную свертку сигналов напряжения из силовой сети и суммарного опорного сигнала от анализируемых гармоник, после операции свертки и дополнительных преобразований получаем приведенные к основной гармонике уровни высших гармонических силового сигнала (рис. 4).

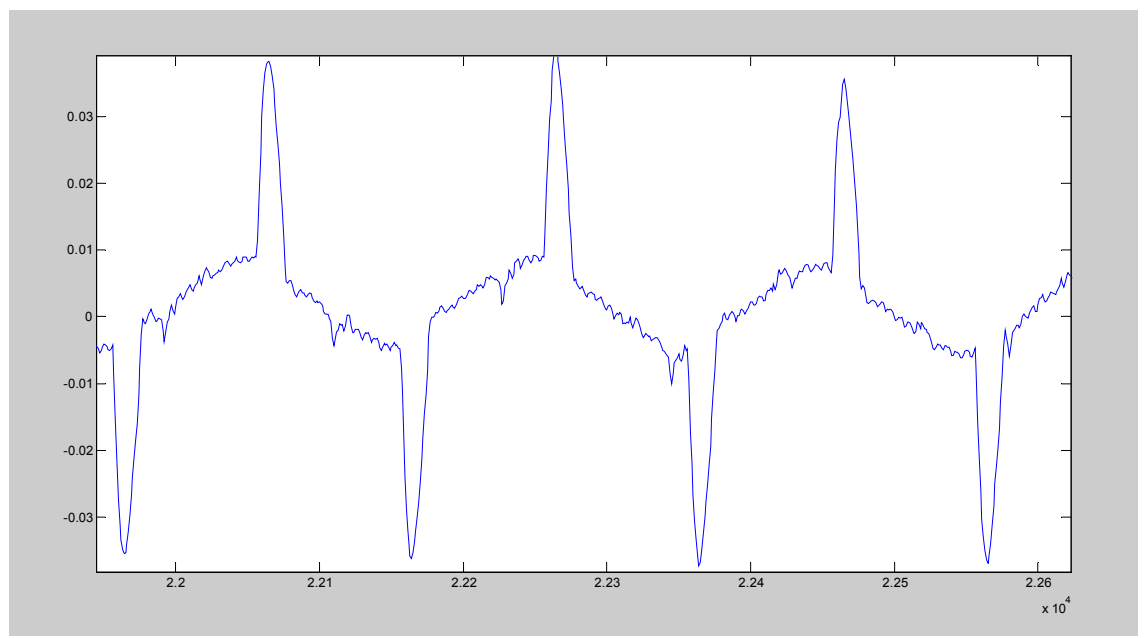

Рис. 3. Осциллограмма напряжения силовой сети

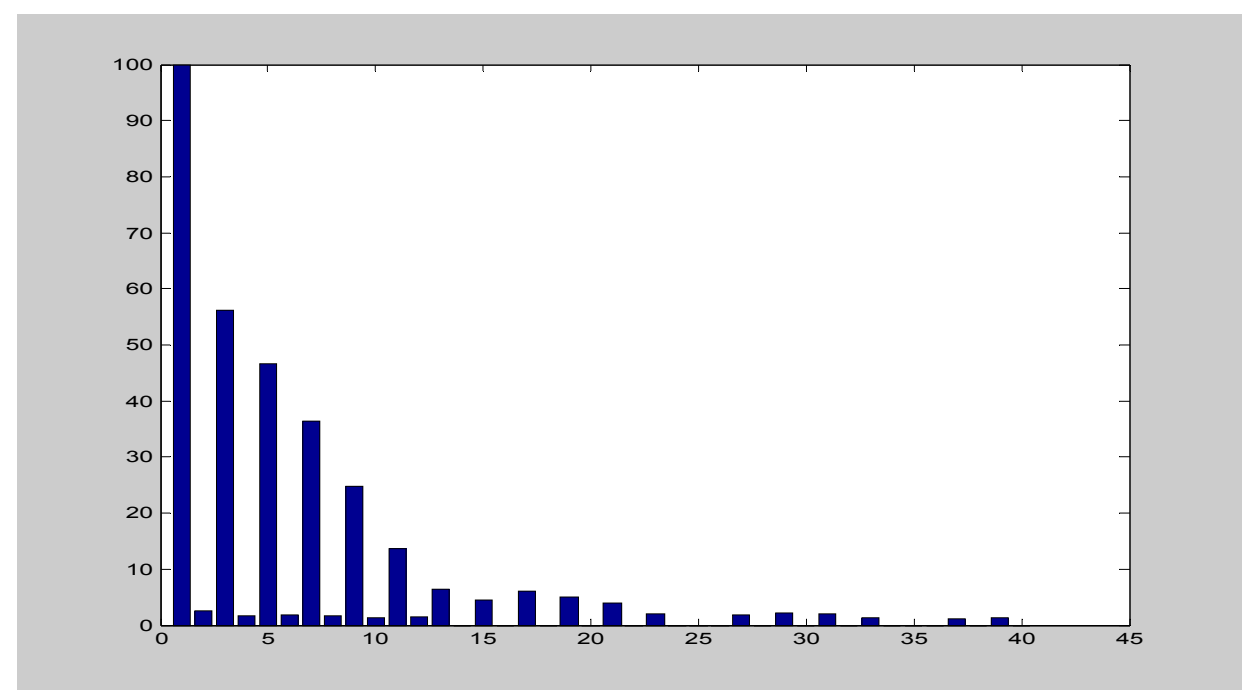

Рис. 4. Анализ высших гармонических напряжения

$$
-931-
$$


Такой способ регистрации высших гармонических сложнее преобразований Фурье или полосовой фильтрации, которые используются в существующих приборах КЭ, однако он позволяет минимизировать как вычислительную погрешность, так и погрешность оцифровки АЦП.

Итоговая погрешность рассмотренного алгоритма анализа гармоник с учетом погрешности звуковой карты составляет менее 1 \%. Данная погрешность была определена опытным путем в результате анализа эталонного сигнала с известным уровнем высших гармонических. Эталонный сигнал был синтезирован с помощью нескольких высокоточных генераторов и прецизионных сумматоров.

Анализируя возможности и характеристики промышленных приборов, контролирующих качество электрической энергии, можно сделать вывод о том, что на базе персонального компьютера (ноутбука) со встроенной или внешней звуковой картой возможно создание анализатора качества электрической энергии, не уступающего, а по некоторым позициям и превосходящего промышленные образцы. 